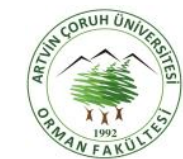

\title{
Kafkas Ihlamuru (Tilia rubra DC. subsp. caucasica) tohumlarinda farklı ekim ortamlarının ve tohum toplama zamanının çimlenme üzerine etkisi
}

\author{
Effects of different germination medium and seed gathering time on Red Lime (Tilia rubra DC. subsp. caucasica) seed \\ germination
}

Güllizar ÖZYURT ${ }^{1}$ (D) , Zafer YÜCESAN ${ }^{1}$

${ }^{1}$ Orman Fakültesi, Orman Mühendisliği Bölümü, Karadeniz Teknik Üniversitesi, 61080, Trabzon/TÜRKiYE

\begin{tabular}{l} 
Eser Bilgisi / Article Info \\
Araştırma makalesi / Research article \\
DOI: 10.17474/artvinofd.659063 \\
\hline Sorumlu yazar / Corresponding author \\
Zafer YÜCESAN \\
e-mail: yucesan@ktu.edu.tr \\
\hline Geliş tarihi / Received \\
13.12.2019 \\
Düzeltme tarihi / Received in revised form \\
27.12.2019 \\
Kabul Tarihi / Accepted \\
09.01.2020 \\
Elektronik erişim / Online available \\
12.03.2020 \\
\hline Anahtar kelimeler: \\
Kafkas ıhlamuru \\
Çimlenme yüzdesi \\
Çimlenme hızı \\
Tohum toplama zamanı \\
Çimlenme ortamı
\end{tabular}

\section{Keywords:}

Red lime

Germination percentage

Germination speed

Seed gathering time

Germination medium

\begin{abstract}
Özet
Çalışma kapsamında Kafkas ıhlamuru (Tilia rubra DC. subsp. caucasica) türünün Karadeniz Teknik Üniversitesi kampüsü içerisinde yer alan üç farklı ağaçtan toplanan tohumları kullanılmıştır. Tohumlar iki farklı tarihte (15 Ağustos 2017 ve 5 Eylül 2017) toplanıp herhangi bir ön işleme tabi tutulmaksızın aynı gün içerisinde ekilmiştir. Ekim ortamı olarak dere kumu ve orman toprağı karışımı (1:2) kullanılmıştır. Sera ve açık alanda oluşturulan ekim yastıklarında ekimler gerçekleştirilmiştir. Açık alanda yapılan ekimlerde gölgeleme yapılan ve yapılmayan deneme parselleri oluşturulmuştur. Çalışma kapsamında en iyi çimlenme yüzdesi \% 59.0 ile 5 Eylül döneminde toplanan tohumlardan açık alanda gölgeleme yapılan ekim yastıklarında elde edilmiştir. En yüksek çimlenme hızı ise Ağustos döneminde, 1 ve 2 no'lu ağaçtan toplanan tohumlarda, açık alanda gölgeleme yapılmayan ekim ortamında 36 gün olarak elde edilmiştir.
\end{abstract}

\begin{abstract}
Red lime (Tilia rubra DC. subsp. caucasica) seeds which were gathered from three different trees located in the Karadeniz Technical University campus were used as a material in this study. Seeds were gathered at two different times (15 August 2017 and 5 September 2017) and sowing was done in the same day without any pre-treatment. A mixture of river sand and forest soil (1:2) was used in germination medium. Three different germination medium (green house, open environment and open environment with shade effect) were used for obtaining germination characteristics. Obtained results showed that best germination percentage occurred in the outside germination medium with shade effect as $59.0 \%$ in seeds which were gathered from the tree 1 in September. However, the best germination speed was obtained as 36 days under the outside environment conditions in seeds gathered from the trees 1 and 2 in August.
\end{abstract}

\section{GíRiş}

Türkiye'de doğal olarak yayılış gösteren ıhlamur türünün dört farklı taksonu bulunmaktadır. Bu dört doğal taksonun Türkiye orman ekosistemi içerisinde yayılış gösterdiği alan büyüklüğüne göre Batı Karadeniz ve Marmara bölgesinde yayılış gösteren Tilia tomentosa türü en büyük paya sahiptir. Kuzeydoğu Anadolu, Isparta, Kazdağı ve Kuşadası'nda yayılış gösteren Tilia platyphyllos türü ikinci sırada yer almaktadır. Kuzeydoğu Anadolu, Aydın, Bolu ve Isparta'da görülen Tilia rubra türü ise üçüncü sırada yer almaktadır. En küçük paya sahip olan Tilia cordata türü ise sonuncu sırada yer almaktadır. (Saatçioğlu 1969, Yaltırık ve Efe 2000, Demir 2003). Ihlamurun ülkemiz ormanlarında 10408 ha normal kapalı, 2166 ha boşluklu kapalı olmak üzere toplamda 12574 ha alanda yayılış gösterdiği ifade edilmektedir (OGM 2015).

Insanoğlunun dünya yüzeyinde var olması ile doğanın dengesinde başlayan değişimlerin, insanlık için rahat yaşam konusunda faydalı ama doğa için sürdürülebilirlik konusunda zararlı etkilerinin olması ile sonuçlanmıştır. İnsanlar, ihtiyaçları için çevreyi ve doğal kaynakları kullanmaya başlayarak çevreden etkilenmiş, aynı zaman da çevreyi de etkilemiştir. Nitekim insanlığın gelişimi sürecinde; değişen zaman, insan ihtiyaçlarının sınırsız oluşu ve doğal kaynakları kullanmada ki bilinçsiz tutumlar çevre ve doğal kaynaklar üzerinde olumsuz etkilere neden olmuştur. Fosil yakıtların kullanımı, ormansızlaşma, arazi kullanımı değişiklikleri ve sanayileşme süreçleri ile küresel ısınma tehdidi hızla 
artmaktadır (Türkeş ve ark. 2000, Akın 2006, Demir 2009). Türlerin doğal yaşam alanları küresel iklim değişikliğinden olumsuz etkilenmekte, hızla gelişen değişime adaptasyonu noktasında sorunlar yaşamalarına neden olmaktadır (Demir 2009).

Ülkemiz ormanlarının floristik açıdan zenginlik göstermesi, hüküm süren ekolojik koşullar açısından zengin varyasyonlar sergilemesinden dolayı odun dışı orman ürünleri açısından da zengin bir potansiyel kaynağıdır. Sağlık ve gıda konusunda ülkelerin ihtiyaçlarını odun dışı orman ürünlerinden elde etmeleri aslında bu ürünlerin sosyo-ekonomik olarak önem teşkil ettiğini göstermektedir. Bu ürünlerin bazı ülkeler de özellikle kırsal fakirliği azaltma konusunda ve yerel ekonominin gelişmesinde önemli katkılarının olduğu görülmektedir (DPT 2001, Killmann ve ark. 2003). Diğer taraftan, odun dışı orman ürünlerinin aşırı otlatma, plansız ve bilinçsizce kullanımdan kaynaklanarak hızla tahrip edilmesi, bu türlerin neslini yok olma tehlikeleri ile karşı karşıya bırakmaktadır (Türker 1998). Nitekim yok olma tehlikelerine karşı odun dışı orman ürün açısından önemli olan türlerin korunması için in-situ (içinde bulundukları ekosistemle birlikte bulundukları yerde korumak) veya ex-situ (yaşadıkları alanın dışında korunması) koruma gibi yöntemlerin kullanılması gerektiği ifade edilmektedir (Kaynak 2001).

Dünya pazarındaki odun dışı orman ürünü olarak yer edinen türlerden biri olan Kafkas Ihlamuru (Tilia rubra DC. subsp. caucasica) türü bulunduğu ülke ekonomisine ve ekolojisine önemli ölçüde değer katmaktadır. Ihraç ettiğimiz odun dışı orman ürünleri arasında yer alan ıhlamur genel olarak bakıldığında $1990^{\prime}$ ।ı yıllarda en yüksek seviyesi olan 469 ton ihracat rakamını bulurken 2000'li yıllarda azalarak 2014 yılında \%84 oranında düşüş yaşayarak 78 tona gerilemiştir (TÜiK 2016, Kurt ve ark. 2016). Diğer taraftan; ağaçlandırma çalışmalarında, peyzaj uygulamalarında, ilaç ve kozmetik sanayiinde, tarım ve hayvancılıkta, yaban hayatı ve doğrudan insan besini gibi birçok kullanım alanı bulunmaktadır.

Ihlamur türleri Fagetum zonu içerisinde yer alan, balçıklı, nemli, verimli topraklarda geniş yayılış alanlarına sahip olsalar da fakir topraklara, rüzgârlı ve hava kirliliğinin olduğu alanlara karşı direnci yüksek, donlara ve kuraklığa karşı duyarlı türlerdir (Rajendra 2009, Pigott 2012). Bu özellikleri ile değişen iklim değişikliğine karşı toleransı olabilecek türlerdendir. Ihlamur türlerinin doğal yayılışı alanlarındaki varlığını devam ettirirken, çoğalma için gerekli olan çevresel koşulların dışında, tohumunun bünyesinde var olan çimlenme engeli nedeniyle birtakım sorunlar yaşamaktadır (Bailey 1961, Vanstone ve Ronald 1982, Pitel ve Wang 1988, Rowe ve Blazich 2008, AlRamamneh ve Qrunflef 2010). Yaşadığı bu sorunlar çimlenmelerde düzensizliklere yol açarak tohumların çimlenme süresini birkaç yıla kadar uzatmaktadır. Dolayısıyla kitlesel fidan üretimi için uygun generatif ve vejetatif üretim tekniklerinin ıhlamur türünde ortaya konması, yayılış alanları içerisinde yaygınlaştııı ıması, iyileştirme çalışmalarına konu edilerek yetişme ortamlarının ıslahı ve ihracatındaki düşüşün toparlanması açısından son derece önemlidir.

Ağılıklı olarak çimlenmesinde ve saklanmasında sorun olan ve uzun süreli katlama süreçlerini gerektiren Kafkas ıhlamuru türünde çimlenme sorunlarının çeşitli yollarla (erken ekim, katlama, çeşitli ön işlemler ve gölgeleme vd.) giderilmesi türün kitlesel fidan üretimi açısından oldukça önemlidir. Tohum toplama zamanı ve ekim ortamlarının çimlenme üzerine etkilerinin araştırılması kapsamında yapılan bu çalışmada; açık alan ve sera koşullarında ön işleme tabi tutulmadan, kendi doğal seleksiyonu içerisinde uyguladığı çimlenme modeli kullanılarak ekilen Kafkas ıhlamuru tohumlarının çimlenme davranışlarının belirlenmesi amaçlanmıştır.

\section{MATERYAL ve YÖNTEM}

\section{Materyal}

Karadeniz Teknik Üniversitesi kampüsü içerinde yer alan Kafkas Ihlamuru ağaçlarından 2017 yılının Ağustos ve Eylül aylarında iki farklı dönemde toplanan tohumlar çalışma materyali olarak kullanılmıştır. Bu kapsamda 3 farklı ağaçtan tohum toplanmıştır. Çalışmada dere kumu ve orman toprağı karıştırılarak (1:2), nem tutma kapasitesi yüksek ve havalanma gücü fazla olabilecek şekilde, Kafkas ihlamuru için ideal olabilecek bir çimlenme ortamı oluşturulmuştur. Hazırlanan bu yetişme ortamları sera içerisinde ve açık alanda hem 
polietilen malzemeden oluşan gölgeleme telisiyle oluşturulmuş gölgeli, hem de gölgesiz olan ekim yastıklarına serilmiştir (Şekil 1). Kapatma materyali olarak da dere kumu ve orman toprağı karışımı (1:2) kullanılmıştır. Ekim ortamlarının aylık sıcaklık ve nem değerleri Çizelge1'de gösterilmiştir

Çizelge 1. Açık alan ve sera içerisindeki aylık ortalama sıcaklık ve nem değerleri

\begin{tabular}{|c|c|c|c|c|c|c|c|c|c|c|c|c|}
\hline \multirow{3}{*}{ AYLAR } & \multicolumn{4}{|c|}{ GÖLGESIZ } & \multicolumn{4}{|c|}{ GÖLGELİ } & \multicolumn{4}{|c|}{ SERA } \\
\hline & \multicolumn{2}{|c|}{$\begin{array}{c}\text { Sıcaklık } \\
\text { (oc) }\end{array}$} & \multicolumn{2}{|c|}{ Nem (\%) } & \multicolumn{2}{|c|}{$\begin{array}{c}\text { Sıcaklık } \\
\text { (oc) }\end{array}$} & \multicolumn{2}{|c|}{ Nem (\%) } & \multicolumn{2}{|c|}{ Sıcaklık (oC) } & \multicolumn{2}{|c|}{ Nem (\%) } \\
\hline & 2017 & 2018 & 2017 & 2018 & 2017 & 2018 & 2017 & 2018 & 2017 & 2018 & 2017 & 2018 \\
\hline Ocak & & 9.3 & & 68.4 & & 7.9 & & 69.7 & & 21.5 & & 67.9 \\
\hline Şubat & & 10.3 & & 72.3 & & 8.8 & & 72.4 & & 22.6 & & 67.4 \\
\hline Mart & & 12.7 & & 70.9 & & 11.2 & & 71.1 & & 21.1 & & 70 \\
\hline Nisan & & 13.3 & & 71.5 & & 11.4 & & 73.5 & & 21.6 & & 72.6 \\
\hline Mayıs & & 19.2 & & 81.4 & & 17.7 & & 83.3 & & 24.6 & & 77.1 \\
\hline Ağustos & 25.7 & & 76.5 & & 23.8 & & 78.7 & & 24 & & 77.6 & \\
\hline Eylül & 22.8 & & 69.5 & & 20.9 & & 69.5 & & 24.8 & & 76.6 & \\
\hline Ekim & 17.1 & & 68.4 & & 15.5 & & 67.5 & & 25 & & 73.6 & \\
\hline Kasım & 13.4 & & 64 & & 11.7 & & 65 & & 21.6 & & 72.6 & \\
\hline Aralık & 11.8 & & 60 & & 9.9 & & 64.3 & & 21.7 & & 71.7 & \\
\hline
\end{tabular}
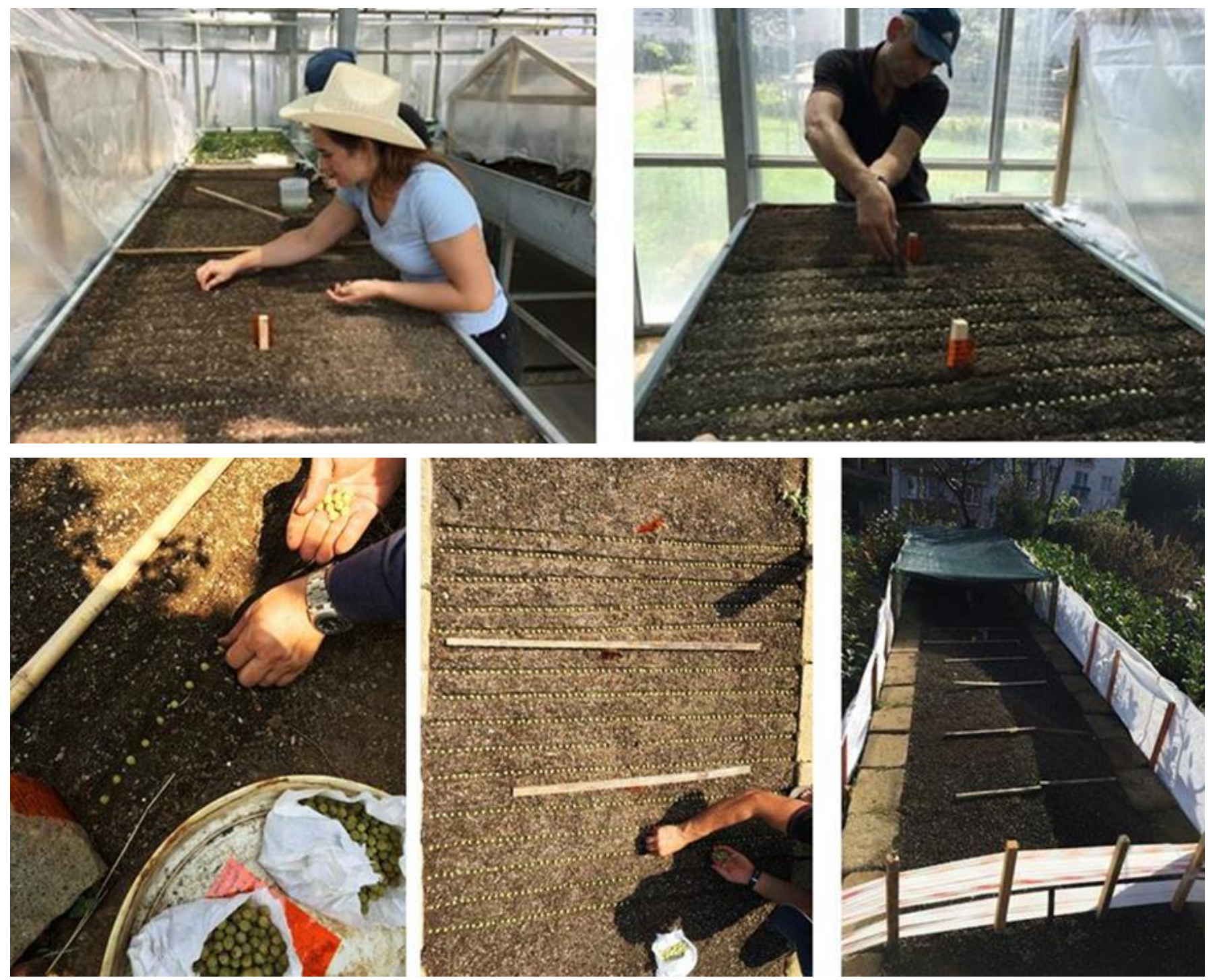

Şekil 1. Ekim yastıklarının genel görünümü (Üstte sera ortamı, altta açık alan gölgeli ve gölgesiz ekim yastıkları) 


\section{Yöntem}

\section{Tohum Toplama Zamanı ve Ekim Yöntemi}

Çalışma kapsamında kullanılan tohumlar yıllanma özelliği kazanmadan yani tam olgunlaşma dönemleri gelmeden toplanarak toplandıkları gün içerisinde sera içerisinde, açık alanda gölge altında ve açık alanda gölgeleme etkisi olmaksızın ekilmiştir. Illk tohumlar 15 Ağustos 2017 tarihinde toplanarak ekilmiştir. İkinci tohum toplama ve ekim tarihi ise 5 Eylül 2017'dir. Toplanan tohumlar Karadeniz Teknik Üniversitesi Orman Fakültesi Araştırma ve Uygulama Serasında dal, yaprak, sap ve brahtelerinden temizlenmiştir. Temizleme işleminden sonra tohumların görsel açıdan yaralı olanları veya kuşlar tarafından hasar verilmiş olanları uzaklaştırılarak ayıklama işlemi yapılmıştır.

Kafkas Ihlamuru tohumlarının ekiminde çizgi ekim yöntemi kullanılmıştır. Hazırlanan yastıklara 5 sıralı ekim çizgisi oluşturulmuştur. Tohumlar her çizgiye 60 adet olacak şekilde $5 \times 60$ örnekleme desenine göre $1-2 \mathrm{~cm}$ derinliğindeki çizgilerin oluşturulduğu yastıklara ekimleri yapılmıştır. Sera ve açık alanda (gölgesiz ve gölgeli) ekim ortamlarına her ağaçtan 300 adet tohum ekilerek, aile bazında 900 adet olmak üzere her dönem için 2700 adet tohum ekimi gerçekleştirilmiştir. Her örneklemenin başına orijin bilgilerini yazan etiketler yerleştirilerek şeritler çekilmiştir. Ekim tamamlandıktan sonra yağmurlama sulama tekniği ile sulama işlemi yapılmış ve ekim süreci tamamlanmıştır.

Çalışma süresi boyunca ekim yastıkları haftada 3 gün sulama işlemi gerçekleştirilmiştir. Yağmurlama sulama tekniği kullanılarak sulama zamanlarında tohumların zarar görmesi engellenmiştir. Sulama ekim yastıklarının her tarafına eşit miktarda olacak şekilde titizlikle yapılmıştır. Sulamanın yanı sıra tohumları hayvanlara karşı korumak için açık alandaki ekim yastıklarının etrafı naylon çuvallarla çevrilmiştir. Çimlenme süresi boyunca yastıklarda büyüyecek olan yabani otlar temizlenerek mücadele yapılmıştır.

Ekim sonrasında ilk çimlenmelerin görüldüğü Şubat ayı itibarı ile sayımlar gerçekleştirilmeye başlanmıs ve bütün ekim ortamları aynı gün aralıkları ile sayıma konu edilmiştir (Şekil 2). Çimlenmelerdeki düzensiz ve orantısız duruma bağı ડ̧ubat-Mayıs dönemi içerisinde birinci sayım ile ikinci sayım arasında 17 gün, ikinci sayımla üçüncü sayım arasında 14 gün, üçüncü sayımla dördüncü sayım ve dördüncü sayım ile beşinci sayım arasında 10 gün, diğer sayımlar arasında ise 7 gün olacak şekilde 100 günlük bir dönem içinde çimlenme sayımları gerçekleştirilmiştir.

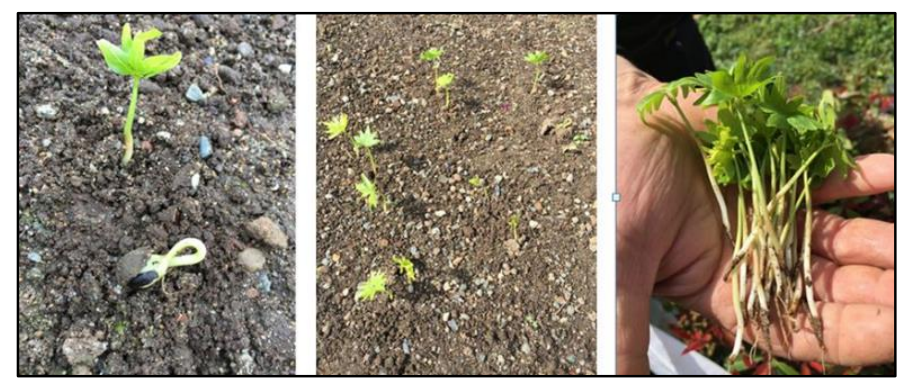

Şekil 2. Ekim yastıklarında tespit edilen çimlenmeler ve fidecik sayımı

\section{Tane Ağırlığının Belirlenmesi}

Temizlenme ve ayıklama işlemleri tamamlanan tohumlardan rastgele 100 adet tohum seçilmiş ve her birey için 8x100 adet tohumun ortalama tane ağırlığı belirlenmiştir. Elde edilen ortalama tane ağırlıkları kullanılarak aşağıda verilen formül yardımıyla ağaç bazında tohum toplanma zamanına bağlı olarak ortalama 1000 tane ağırlığı değerleri hesaplanmıştır (ISTA, 1993).

1000 Tane ağırlığ $=\left(\left(\sum x i\right) \div n\right) \times 10$

Formülde;

$\sum x i=$ Yinelemelerin 100 adet tohum ağırlıkları (gr)

$\mathrm{n}=$ yineleme sayısını ifade etmektedir.

\section{Çimlenme Hızlarının ve Yüzdelerinin Belirlenmesi}

Çimlenme hızı tespitinde aşağıdaki formül kullanılmıştır (Ellis and Roberts 1980):

Çimlenme Hızı $=\frac{\left(\sum n i\right) \times\left(\sum t i\right)}{T}$

Formülde;

$n i=$ belirli bir gün sayısını,

$t i=$ belirli bir gün sayısında çimlenen tohumların sayısı

$T=$ toplam çimlenmiş tohum sayısını gösterir,

Çimlenme yüzdesi, tohumların çimlenme özelliklerinin gözlemlendiği 100 günlük periyot içerisinde çimlenen 
toplam tohum sayısı ekilen tohum sayısına oranlanarak hesaplanmıştır (Bewley ve Black 1994).

Çimlenme Yüzdesi $=\left(\left(\sum x i\right) \div N\right) \times 100$

Formülde;

$x i: i$. Gündeki çimlenen sayısı,

$N$ : Teste konulan toplam tohum sayısını ifade etmektedir.

\section{İstatistiksel Analiz}

Çalışmada çimlenme yüzdesi ve çimlenme hızı açısından gruplar arasında fark olup olmadığını test etmek amacıyla öncelikli olarak verilerin normal dağılım gösterip göstermediğini normallik testi yapılarak kontrol edilmiştir. Normallik testi için veri setlerinin basıklık, çarpıklık değerleri ile Shapiro-Wilk ve KolmogorovSmirnov değerlerine bakılmıştır. Basıklık ve çarpıklık değerleri +1.5-1.5 arasında olması durumunda ya da p $>0.05$ olması durumunda verilerin normal dağılım gösterdiği kabul edilmiştir (Tabachnick ve Fidell 2013). Normal dağılım gösteren verilen istatistiksel analizi için ANOVA ve T Testi kullanılarak, çimlenme yüzdesi ve çimlenme hızı açısından gruplar arasında istatistiksel olarak anlamlı $(p<0.05)$ fark olup olmadığı belirlenmiştir. İstatistiksel olarak anlamlı farklııkların çıkması durumunda Duncan Testi uygulanarak homojen gruplar tespit edilmiştir.

\section{BULGULAR VE TARTIŞMA}

\section{Tane Ağırlığına İlişkin Bulgular ve Tartışma}

Aile bazında toplanan tohumlardan oluşturulan $8 \times 100$ adet tohum örneklerinin ortalama ağırlıkları Çizelge 2'de verilmiştir.

Çizelge 2. Tohumların Tane Ağırlıkları

\begin{tabular}{|c|c|c|c|c|c|c|c|}
\hline & \multicolumn{3}{|c|}{ 1. Dönem tane ağırlığı (g) } & & \multicolumn{3}{|c|}{ 2. Dönem tane ağırlığı (g) } \\
\hline & 1. ağaç & 2. ağaç & 3. ağaç & & 1. ağaç & 2. ağaç & 3. ağaç \\
\hline 1 & 41.56 & 45.34 & 45.09 & 1 & 37.33 & 43.48 & 17.45 \\
\hline 2 & 38.42 & 44.98 & 41.13 & 2 & 36.30 & 40.84 & 19.41 \\
\hline 3 & 39.77 & 41.23 & 40.78 & 3 & 34.45 & 44.54 & 19.70 \\
\hline 4 & 38.67 & 43.49 & 42.97 & 4 & 35.32 & 41.71 & 16.95 \\
\hline 5 & 40.73 & 45.78 & 41.43 & 5 & 34.93 & 42.38 & 18.98 \\
\hline 6 & 40.58 & 43.47 & 45.57 & 6 & 37.88 & 44.92 & 20.30 \\
\hline 7 & 41.93 & 42.88 & 43.05 & 7 & 33.27 & 43.16 & 22.38 \\
\hline 8 & 40.22 & 44.31 & 42.07 & 8 & 34.32 & 42.63 & 17.63 \\
\hline 1000 Tane Ağırlığı & 402.3 & 439.3 & 427.6 & & 354.8 & 429.6 & 191.0 \\
\hline
\end{tabular}

Bireylerin ortalama 1000 tane ağırlıkları, tohum toplama zamanına bağı olarak dönemsel farklılıklar göstermektedir. 1 no'lu ağaçta 15 Ağustos'ta toplanan tohumların ortalama tane ağırlığı 402.3 gr, 05 Eylül'de toplanan tohumların 355.0 gr'dır. 2 no'lu ağaçtan ölçümlenen ortalama tane ağırlıkları 15 Ağustos döneminde toplanan tohumların 439.4 gr, 05 Eylül döneminde toplanan tohumlarınsa $429.6 \mathrm{gr}$ olduğu görülmüştür. 3 no'lu ağaçtan toplanan tohumların ise 15 Ağustos dönemindeki tane ağırlığı 427.6 gr, 05 Eylül döneminde toplanan tohumların $191.3 \mathrm{gr}$ olduğu görülmüştür.
Yapılan çalışmada, Kafkas ıhlamuru tohumlarının ortalama 1000 tane ağırlıklarına ilişkin bulunan sonuçlarda, tohum toplamam zamanı ve aile bazına göre farklılıkların olduğu gözlemlenmiştir. Nitekim Üçler ve Kadıoğlu (2010) yaptıkları çalışmalarında, Kafkas ıhlamuru türünde ortalama tane ağırlığının, farklı tohum toplama zamanına göre değiştiğini ifade etmektedir. Diğer taraftan, ıhlamur türünde yapılan başkaca çalışmalarda da, ortalama 1000-tane ağırlığı değerlerinin tohumlarının orijinlerine ve çevresel faktörlere bağlı olarak değişebildiği ifade edilmektedir (Özpay 1998, Na ve ark. 2011). Schmidt (2000), yaptığı bir çalışmada tohum boyutu ve ağırlı̆̆ı gibi morfolojik özelliklerin farklı olmasında aile farklılığın yanı sıra kalıtımsal ve çevresel 
faktörlerin de etkisinin olduğunu vurgulamıştır. Tohum ağırlığı ve boyutlarının; popülasyonlara, bireylere, yaşa, tohumun bitki üzerindeki konumuna, bonitet, nem, sıcaklık ve ışık gibi çevresel faktörlere bağlı olarak da değişebildiği ifade edilmektedir (Stroempl 1968, Copeland ve Mcdonald 2001). Ayrica, Wood ve ark. (1977), bitkiler arası rekabet, zararlı böcek ve hastalıkların da tohum boyutunda etkili olduğunu belirtmişlerdir.

\section{Çimlenme Yüzdesi ve Çimlenme Hızlarına İlişkin Bulgular ve Tartışma}

Kafkas ıhlamuru tohumlarında ön işlem uygulamaksızın farklı üç ağaçtan, farklı iki dönemde toplanan tohumların açık alan ve sera koşullarında ekimleri yapılarak elde edilen sonuçlarda, açık alan koşullarında ekimi yapılan ekimlerde çimlenme meydana gelmiş fakat sera koşullarında ekimi yapılan tohumlarda çimlenme meydana gelmemiştir. Nitekim, Özana (2019) ve Ebcin Korkusuz (2014), sera koşullarındaki ekimlerde sera ortam sıcaklığının yüksek olmasına bağlı olarak çimlenme yüzdesinin olumsuz etkilendiğini ifade etmektedir.

Yapılan normallik testi sonucunda çimlenme yüzdesi ve çimlenme hızı verilerinin normal dağııım gösterdiği belirlenmiştir (Çizelge 3 ve Çizelge 4). Bu kapsamda yapılan varyans analizi sonucunda çimlenme yüzdeleri aile, tohum toplama zamanı ve ekim ortamı faktörlerine bağlı olarak $p<0.05$ güven düzeyinde istatistiki açıdan anlamlı farklılıklar gösterirken, deneme deseni faktörü yönünden uygulanan varyans analizi sonucunda çimlenme hızı değişkeninde istatistiki açıdan anlamlı farklılık ortaya çıkmamıştır. Elde edilen sonuçlara göre çimlenme yüzdelerinin aile, tohum toplama zamanı ve ekim ortamına bağlı olarak anlamlı farklılıklar gösterdiği (Çizelge 5), çimlenme hızları açısından ise araştırmaya konu deneme deseni içerisinde anlamlı farklılıkların olmadığı tespit edilmiştir (Çizelge 6). Duncan Testi sonuçlarına göre, aile bazında 1 ve 3 no'lu ağaçlar çimlenme yüzdesi açısından aynı grupta yer alırken, 2 no'lu ağaç farklı grupta yer almıştır (Çizelge 7).

Çizelge 3. Çimlenme yüzdesi Normalite Testi sonuçları

\begin{tabular}{ccccc}
\hline & $\begin{array}{c}\text { Çarpıklık } \\
\text { (Skewness) }\end{array}$ & $\begin{array}{c}\text { Standart } \\
\text { Sapma }\end{array}$ & $\begin{array}{c}\text { Basıklık } \\
\text { (Kurtosis) }\end{array}$ & Standart Sapma \\
\hline Çimlenme Yüzdesi & 1.191 & 0.309 & 0.125 & 0.608 \\
Çimlenme Yüzdesi & Shapiro Wilk & & & P \\
& 0.798 & & $0.000^{*}$ &
\end{tabular}

*Önem düzeyi $(\mathrm{P})>0.05$ istatistiksel olarak fark var

Çizelge 4. Çimlenme hızı Normalite Testi sonuçları

\begin{tabular}{ccccc} 
& $\begin{array}{c}\text { Çarpıklık } \\
\text { (Skewness) }\end{array}$ & $\begin{array}{c}\text { Standart } \\
\text { Sapma }\end{array}$ & $\begin{array}{c}\text { Basıklık } \\
\text { (Kurtosis) }\end{array}$ & Standart Sapma \\
\hline Çimlenme Hızı & 1.035 & 0.309 & 1.453 & 0.608 \\
Çimlenme Hızı & \multicolumn{2}{c}{$\begin{array}{c}\text { Shapiro Wilk } \\
0.875\end{array}$} & & $0.000 *$ \\
\hline
\end{tabular}

*Önem düzeyi $(\mathrm{P})>0.05$ istatistiksel olarak fark var

Çizelge 5. Tilia rubra tohumlarının çimlenme yüzdelerine ilişkin Varyans Analizi sonuçları

\begin{tabular}{|c|c|c|c|c|c|}
\hline Varyans Kaynağı & Kareler Toplamı & Serbestlik Derecesi & Kareler Ortalaması & $\mathbf{F}$ & $\mathbf{P}$ \\
\hline $\begin{array}{c}\text { Ağaç } \\
\text { Tohum Top. Zamanı }\end{array}$ & 2410.321 & 2 & 1205.161 & 63.432 & $0.000 *$ \\
\hline $\begin{array}{c}\text { Ağaç } \\
\text { Ekim Ortamı }\end{array}$ & 903.868 & 2 & 451.934 & 23.787 & $0.000^{*}$ \\
\hline $\begin{array}{c}\text { Tohum Top. Zamanı } \\
\text { Ekim Ortamı } \\
\text { Ağaç }\end{array}$ & 1026.721 & 1 & 1026.721 & 54.040 & $0.000 *$ \\
\hline $\begin{array}{l}\text { Tohum Top. Zamanı } \\
\text { Ekim Ortamı }\end{array}$ & 972.485 & 2 & 486.243 & 25.593 & $0.000^{*}$ \\
\hline
\end{tabular}

*Önem düzeyi $(\mathrm{P})<0.05$ istatistiksel olarak fark var 
Çizelge 6. Tilia rubra tohumlarının çimlenme hızlarına ilişkin Varyans Analizi sonuçları

\begin{tabular}{|c|c|c|c|c|c|}
\hline Varyans Kaynağı & Kareler Toplamı & Serbestlik Derecesi & Kareler Ortalaması & $\mathbf{F}$ & $\mathbf{P}$ \\
\hline $\begin{array}{c}\text { Ağaç } \\
\text { Tohum Top. Zamanı }\end{array}$ & 54.296 & 2 & 27.148 & 1.042 & $0.360^{*}$ \\
\hline $\begin{array}{c}\text { Ağaç } \\
\text { Ekim Ortamı }\end{array}$ & 111.550 & 2 & 55.775 & 2.142 & $0.129 *$ \\
\hline $\begin{array}{l}\text { Tohum Top. Zamanı } \\
\text { Ekim Ortamı } \\
\text { Ağaç }\end{array}$ & 7.018 & 1 & 7.018 & .269 & $0.606^{*}$ \\
\hline $\begin{array}{l}\text { Tohum Top. Zamanı } \\
\text { Ekim Ortamı }\end{array}$ & 144.397 & 2 & 72.198 & 2.772 & $0.073 *$ \\
\hline
\end{tabular}

Çizelge 7. Çimlenme yüzdelerine ilişkin Duncan testi sonuçları

\begin{tabular}{ccc}
\hline Ağaç_no & \multicolumn{1}{c}{ Önem Düzeyine Göre Gruplandırma (P>0.05) } \\
\cline { 2 - 3 } & 1 & 2 \\
\hline no'lu ağaç & 5.03 & 21.83 \\
3 no'lu ağaç & & 22.73 \\
1 no'lu ağaç & & \\
\hline
\end{tabular}

Açık alan gölgeleme ve gölgeleme olmadan tohum ekimi uygulanan ortamlarda çimlenme yüzdeleri ve çimlenme hızları değerlendirildiğinde, aile bazında en iyi çimlenme yüzdeleri sırasıyla 3, 1 ve 2 no'lu ağaçta $\% 59$, $\% 47$ ve $\%$ 10,7 , çimlenme hızları ise 57,56 ve 72 gün olarak tespit edilmiştir (Çizelge 8). Aile bazında istatistiksel olarak anlamlı çimlenme yüzdesi ve çimlenme hızının farklııkları genetik varyasyona bağıı olarak çimlenme yüzdesinin değişebileceği şeklinde yorumlanabilir (Yoon ve Kim 1994, Üçler ve Kadıoğlu 2010, Ebcin Korkusuz 2014, Özana 2019). Diğer taraftan, gölge ortamı ektisine bağlı olarak ortam neminin daha yüksek olmasının, tohumun bünyesinde var olan nem oranın düşmemesine neden olduğu, bunun da çimlenme yüzdesini olumlu etkilediğini ifade etmek de mümkündür.

Çizelge 8. Tohumların çimlenme yüzdeleri ve çimlenme hızları

\begin{tabular}{|c|c|c|c|c|c|}
\hline \multirow{3}{*}{$\begin{array}{c}\text { Tohum Toplama Zamanı } \\
\text { Çim. Yüzdesi } \\
(\%)\end{array}$} & \multicolumn{2}{|c|}{1 no'lu ağaç/gölgeleme } & \multicolumn{3}{|c|}{1 no'lu ağaç/gölgeleme yok } \\
\hline & 1. Dönem & 2. Dönem & 1. & Dönem & 2. Dönem \\
\hline & 10.4 & 47.0 & & 1.0 & 32.5 \\
\hline $\begin{array}{l}\text { Çim. Hızı } \\
\text { (gün) }\end{array}$ & 41 & 56 & & 36 & 47 \\
\hline Ağaç No/Uygulama & \multicolumn{2}{|c|}{2 no'lu ağaç/gölgeleme } & \multicolumn{3}{|c|}{2 no'lu ağaç/gölgeleme yok } \\
\hline Tohum Toplama Zamanı & 1. Dönem & 2. Dönem & 1. & Dönem & 2. Dönem \\
\hline $\begin{array}{c}\text { Çim. Yüzdesi } \\
\text { (\%) }\end{array}$ & 0.7 & 10.7 & & 2.0 & 6.7 \\
\hline $\begin{array}{l}\text { Çim. Hızı } \\
\text { (gün) }\end{array}$ & 62 & 72 & & 36 & 59 \\
\hline Ağaç No/Uygulama & \multicolumn{2}{|c|}{3 no'lu ağaç/gölgeleme } & \multicolumn{3}{|c|}{3 no'lu ağaç/gölgeleme yok } \\
\hline Tohum Toplama Zamanı & 1. Dönem & 2. Dönem & 1. & Dönem & 2. Dönem \\
\hline $\begin{array}{c}\text { Çim. Yüzdesi } \\
\text { (\%) }\end{array}$ & 5.0 & 59.0 & & 4.3 & 19.0 \\
\hline $\begin{array}{l}\text { Çim. Hızı } \\
\text { (gün) }\end{array}$ & 57 & 57 & & 40 & 53 \\
\hline
\end{tabular}

Kafkas ıhlamuru tohumlarının toplanma zamanı olarak belirlenen 1 . ve 2 . dönemlerinin çimlenme yüzdelerinin ve çimlenme hızlarının değerlendirilmesi yapıldığında; 2. dönemdeki tohumların çimlenme yüzdesi \% 29,2 çimlenme hızı ise 57 gün, 1. dönemde toplanan tohumların çimlenme yüzdesi \% 3,90 çimlenme hızının 
ise 45 gün olduğu tespit edilmiştir. Elde edilen sonuçlara göre, tohum toplama zamanı olarak tam olgunlaşmadan toplanan tohumların ekim ortamına ekimi yapıldıktan sonra ekim ortamındaki sıcaklık ve nem değerlerinin gölgeleme ile kontrol altında tutulmasının çimlenme yüzdesini olumlu yönde, çimlenme hızına ise olumsuz yönde etkide bulunduğunu söylemek mümkündür. Dolayısıyla, tohumun olgunlaşma zamanının çimlenme yüzdesindeki başarıya olumlu yönde katkılar sağladığı anlaşılmaktadır. Nitekim, yapılan bazı çalışmalarda Ağustos ayının sonu ile Eylül ayının ilk haftasında daha iyi çimlenme başarısının olduğu ifade edilmektedir (Yoon ve Kim 1994, Dirr ve Heuser 2006, Bonner ve Karrfalt 2008, Molashahı ve ark. 2008, Üçler ve Kadıoğlu 2010, Ebcin Korkusuz 2014). Diğer taraftan, bazı fidanlık çalışmalarında ıhlamur tohumlarının yarı olgunlaşmış dönem içinde erken toplanıp ekilmesi durumunda, tohumlarda meydana gelebilecek dormansinin kış döneminde giderilerek ilkbaharda çimlenmelerin gerçekleştiği belirtilmektedir. Tohumun tam olgunlaştığı dönem içinde geç toplandığında ise yıllanma özelliği kazandığı ve ikinci ilkbaharda çimlenmelerin gerçekleştiği ifade edilmektedir (Veselinovic 2001, Dirr ve Heuser 2006, Molashahı ve ark. 2008, Üçler ve Kadıoğlu 2010).

\section{SONUÇ}

Çimlenme başarısı üzerinde tohum toplama zamanının etkisi bulunmaktadır. Tohum toplama zamanı açısından, tohum tam olgunlaşmadan Eylül ayının ilk haftasında toplanıp ekilmesi durumunda, kış boyu toprak altında kalarak doğal katlama sürecini yaşamaktadır. Bu süreç ardından, ilkbahar döneminde gerçekleşen çimlenmelerde başarı yüzdesi artmaktadır. Dolayısıyla, Kafkas ıhlamuru türünde Eylül ayının ilk haftasında tohum toplanarak çimlenme deneylerinin gerçekleştirilmesi çimlenme yüzdesinin artması için tavsiye edilebilir.

Açık alan gölge ekimlerinin çimlenme yüzdesi açısından başarılı sonuçlar vermesi, açık alan ekimlerinde gölgelemenin çimlenme üzerine mutlak bir etkisinin olduğu ve tohumun bünyesindeki nemin kaybını önleyici bir etken olabileceğini düşündürmektedir. Gölgelemenin Kafkas ıhlamuru için doğal ortamındaki süreç taklit edilerek, açık alan ekimlerinde ekim yastıklarının üzerinin bir örtü ile kapatılarak sıcaklık ve rutubet kontrolünün yapılması çimlenme başarısını artırmak açısından önerilebilir.

Aile bazında ağaçlar arası çimlenme yüzdelerinin farklılıklar göstermesi seçilecek bireylerin büyüme ve kalite özellikleri açısından türün doğal yayılış alanını temsil niteliği taşımalıdır. Bu bağlamda, yüksek çimlenme başarısı elde edebilmek için, doğal yayılış alanları içerisinden kaliteli bireylerden tohumların alınıp çalışılması gereklidir.

Çalışma kapsamında, Kafkas ıhlamuru türünün doğadaki doğal tohum dökümü zamanı örneklenerek tohumlara ekim öncesi ön işlem uygulaması yapılmamıştır. Dolayısıyla tohumların doluluk oranları tespit edilmemiştir. Çimlenme yüzdeleri belirlenirken ekilen tohumlarda boş tohum olma olasılığı bulunmaktadır. Dolayısıyla, bu konuda ileride yapılacak daha detaylı çalışmalarda, dolu tohumlar tespit edilerek gerçekleştirilecek deneme desenlerinde, bu çalışma kapsamında uygulanmış işlemlerin ya da farklı işlemlerin, farklı çimlenme başarısı değerlerini ortaya koyabileceği dikkate alınmalıdır. Diğer taraftan, sera koşullarında tohumlarının çimlenmesi için gerekli olan sıcaklık ve nem değerlerinin sabit tutulacağı iklim kontrollü denemelerin yapılması daha yüksek çimlenme başarısı elde etmek için denenmelidir.

\section{TEŞEKKÜR}

Bu çalışma, Karadeniz Teknik Üniversitesi Fen Bilimleri Enstitüsü Orman Mühendisliği Anabilim Dalında Doç. Dr. Zafer YÜCESAN'ın danışmanlığında hazırlanan "Kafkas ıhlamuru (Tilia rubra DC. subsp. caucasica) tohumlarında farklı ekim ortamlarının ve tohum toplama zamanının çimlenme üzerine etkilerinin analizi" isimli yüksek lisans tezi verileri kullanılarak hazırlanmıştır. Yüksek lisans tezine katkılarından dolayı Prof. Dr. Ali Ömer ÜÇLER'e teşekkür ederiz.

\section{KAYNAKLAR}

Akın G (2006) Global Warming, Causes and Results. Ankara University Journal of Language and History-Geography, 46 (2): 29-43. 
Al-Rahamneh EXAM, Qrunfleh MM (2010) Propagation of Tilia argentea by seeds and stem cuttings, their cultivation and aspects of uses. The 2 nd international symposium on medicinal plants, Abstract Book, Petra-Jordan, pp 99-100.

Bailey CV (1961) Early collection and immediate sowing increase germination of Basswood (Tilia americana) seed. Tree Planters' Notes 46: 27-28.

Bewley JD, Black M (1994) Seeds Physiology of Development and Germination. 3rd Edition, Plenum Press, New York, 445 p.

Copeland LO, Mcdonald MB (2001) Principles of Seed Science and Technology. 4th Edition edn. Kluwer academic publications, Norwell, Massachusetts, $467 \mathrm{p}$.

Demir A (2009) Küresel İklim Değişikliğinin Biyolojik Çeşitlilik ve Ekosistem Kaynakları Üzerine Etkisi. Ankara Üniversitesi Çevre Bilimleri Dergisi, 1(2): 37-54.

Demir D (2003) Türkiye'de Doğal Yetişen Ihlamur (Tilia L) Taksonlarının Morfolojik ve Palinolojik Özellikleri, i.ü. Fen Bilimleri Enstitüsü, Yüksek Lisans Tezi, İstanbul, $178 \mathrm{~s}$.

Dirr MA, Heuser CW (2006) Reference Manual of Woody Plant Propagation. Varsity Press, North Carolina, $410 \mathrm{p}$.

DPT (2001) VIII. Beş Yıllık Kalkınma Planı. Ormancılık Özel ihtisas Komisyon Raporu, Devlet Planlama Teşkilatı Yayınları, ISBN 97519-2555-X, Ankara, 539 s.

Ebcin Korkusuz E (2014) Gümüşi Ihlamurun (Tilia Tomentosa Moench.) Tohum Özellikleri Üzerine Araştırmalar, iü Fen Bilimleri Enstitüsü, Doktora Tezi, İstanbul, $202 \mathrm{~s}$.

Ellis RH, Roberts EH (1980) Towards a rational basis for testing seed quality. In Seed Production, Butterwooths, London pp 605-645.

ISTA (International Seed Testing Association) (1993) Rules For Testing Seeds: Rules, Seed Science and Technology, 21 (Suppl.): pp. 1-259

Kaynak S (2001) Biyolojik Çeşitlilik ve Çevre Koruma Rehberi. Kardelen, Ankara. 975- 93611-1-6.

Killmann W, Ndeckere F, Vantomme P ve Walter S (2003) Developing inventory methodologies for the elaboration of national level statistics on NWFP: Lessons learned from case studies and from a global assessment. Sustainable Production of Wood and NonWood Forest Products, March 11-12, New Zealand, 604 (5): 8387.

Kurt R, Karayılmazlar S, İmren E, Çabuk Y (2016) Türkiye Ormancılık Sektöründe Odun Dışı Orman Ürünleri: İhracat Analizi, Journal of Bartın Faculty of Forestry, 18(2): 158-167.

Molashahi M, Hosseini SM, Bayat D, Naseri B, Razaee A, Vatani L (2009). Effect of collection time on germination and viability of Tilia platyphylus (Basswood). Iranian Journal of Forest and Poplar Research, 16 (3): 478-485.

OGM (2015) Türkiye Orman Varlığı 2016-2017 pdf. Türkiye Cumhuriyeti Orman ve Su İşleri Bakanlığı Orman Genel Müdürlüğü Yayınları, Ankara, 32s.

Özana (2019) Ihlamur (Tilia rubra) Tohumlarının Çimlenmesi Üzerine Bazı Öz İşlemlerin Etkisinin Araştırılması. Artvin Çoruh Üniversitesi Fen Bilimleri Enstitüsü, Yüksek Lisans Tezi, Artvin, 34s.

Özpay Z (1998) Ihlamur'un (Tilia L.) tohum ve çelikle yetiştirilmesi imkanları üzerine araştırmalar. Batı Karadeniz Ormancılık
Araştırma Enstitüsü Müdürlüğü Teknik Bülten 2, Yayın no: 4 ISSN: 1301-2207, Ankara.

Pigott D (2012) Lime-trees and basswoods: A biological monograph of the genus Tilia. Cambridge university press, New York, 405 p.

Pitel J, Wang B (1988) Improving germination of Basswood (Tilia americana L.) seeds with gibberellic acid. Seed Science and Technology, 16: 273-280.

Rajendra K (2009) Species differentiation in Tilia: A genetic approach. Georg-August University, M. Sc. Thesis, Goettingen, Germany, $108 \mathrm{p}$.

Rowe DB, Blazich FA (2008) The Woody Plant Seed Manual. In: Franklin T. Banner and Robert P. Karrfalt (ed). Tiliaceae-Linden family T Tilia L. linden or basswood. Agriculture Handbook 727, United States Department of Agriculture (USDA), Forest Service, , pp 1113-1118.

Saatçioğlu F (1969) Silvikltür-ı (Silvikültürün Biyolojik Esasları ve Prensipleri). i.ü. Orman Fakültesi Yayın No:138, İstanbul, 323s.

Schmidt L (2000) Guide to Handling of Tropical and Subtropical Forest Seed. Danida Forest Seed Centre. Humlebaek, Denmark, 511p.

Stroempl G (1968) Relationships of fruit and seed form, size, weight and soundness of graded basswood fruit. Tree Plant., 19: 22-28.

Tabachnick BG, Fidell LS (2013) Using Multivariate Statistics, Pearson, $1032 p$.

TÜiK (2016) Türkiye İstatistik Kurumu Kayıtları. Ankara.

Türker MF (1998). Orman İşletme Ekonomisi Ders Notu, KTÜ Orman Fakültesi, Ders Notları Serisi Yayını No:59, Trabzon.

Türkeş M, Sümer UM ve Çetiner G (2000) ‘Global Climate Change and Possible Effects', Ministry of Environment, The United Nations Framework Contract on Climate Change Seminar Notes (13 April 2000, İstanbul Chamber of Industry), 7-24, ÇKÖK General Directorate, Ankara.

Üçler AÖ, Kadıoğlu MD (2010) Effect of different seed collectionsowing date and sowing media on germination in the caucasıan linden (Tilia rubra DC.), The 1st International symposıum on Enviroment and Forestry, Trabzon, pp 252-263.

Vanstone D, Ronald W (1982) Seed germination of American basswood in relation to seed maturity. Canadian Journal of Plant Science, 62: 709-713.

Veselinovic M (2001) The importance of recognizing the morphological changes during the development ahenia seed of white linden (Tilia tomentosa Moench.) for the term determination of its picking and planting. Collection-institute of forestry, 44.

Wood DW, Longden PC, Scott RK (1977) Seed size variation, its extent, source and significance in field crops. Seed Sci. Technol., 2: 337352.

Yaltırık F, Efe A (2000) Dendroloji Ders Kitabı, i.ü. Orman Fak. Yayın No: 465 , ìstanbul.

Yoon J, Kim J (1994) The effect of seed-collecting times on the embryo maturity and germination rate of Tilia mandshurica and Acer triflorum. The Research Reports of the Forestry Research Institute, 50p. 